\title{
GMR
}

\section{A study on natural recovery of tassel fertilization and doubling method in maize haploids}

\author{
L. Jiang*, X.Y. Yang*, X.Y. Li*, P.K. Deng, G.X. Jing, X.Q. Wang, \\ Z. Xing and R.G. Zhao
}

School of Agronomy, Jilin Agriculture University, Changchun, Jilin Province, China

*These authors contributed equally to this study.

Corresponding author: R.G. Zhao

E-mail: jianglong335@sina.com

Genet. Mol. Res. 16 (1): gmr16019173

Received September 5, 2016

Accepted December 15, 2016

Published March 22, 2017

DOI http://dx.doi.org/10.4238/gmr16019173

Copyright (C) 2017 The Authors. This is an open-access article distributed under the terms of the Creative Commons Attribution ShareAlike (CC BY-SA) 4.0 License

\begin{abstract}
Doubling method is the technical barriers in maize haploid breeding. It was very important to establish the independent intellectual property rights for doubling method. In this experiment, the maize haploid inducer, TG15, was used for producing maternal haploids. Also, haploids were obtained from two kinds of maternal genotypes involved in the experiment, including high-oil type and common type. Significant differences were observed among offspring of various genotypes in the recovery of haploid fertilization. In 21 hybrid offspring haploids, the average powder rate was $8.28 \%$, and the seed setting rate was $4.98 \%$. The experimental results showed that when the hybrids were treated with $0.08 \%$ colchicine, the average powder rate and seed setting rate of offspring haploids were 35.53 and $20.30 \%$, respectively, which were significantly higher than the hybrids with natural recovery ability. This study primarily established the doubling method of haploids called "bud seedling method" in China which was very practicably in maize doubled haploid breeding.
\end{abstract}

Key words: Haploid; Maize; Recovery of haploid fertilization; Bud seedling method

Genetics and Molecular Research 16 (1): gmr16019173 


\section{INTRODUCTION}

In recent years, seed companies have regarded haploid technology as the main breeding technology of maize inbred lines in developed countries, and they have established a special "doubled haploid (DH) production department" for producing the homozygous inbred lines in the commercial maize breeding system at a large scale (Jiang et al., 2014; Dong et al., 2015). In China, many studies have focused on the application of maize haploid technology, including the selection of induction system, hybrid induction, doubling method, technical specification of haploid, etc. (Xu et al., 2012, 2013; Cai et al., 2013). Following the continuous selection of new induced lines and increasing induction rate of haploid, it is important to improve the doubling rate immediately. The chromosome doubling and $\mathrm{DH}$ system was needed to produce haploids for breeding. The main technological obstacle in the haploid breeding technology is the doubling method of haploids, which is also the important reason that haploid breeding could not be applied broadly. Many scientific research institutions and companies consider the haploid breeding as the routine way to produce inbred lines; however, these methods could not be applied because they were in a state of securing patent protection (Prigge et al., 2012; Zhao et al., 2013). Therefore, we considered developing a doubling method with independent intellectual property rights for promoting the development of haploid technology in our country. The aim of this study was to explore a distinctive doubling method to improve the rate of haploid breeding.

\section{MATERIAL AND METHODS}

\section{Induction and primary identification of haploid}

The hybrids with large cultivated area in the northeast of China (NH101, ZD958, XY335, HO5598, and HO115) and some cross combinations with high yield (JNTG1-JNTG16) were selected and planted in Jilin Agricultural University experimental station (Changchun, N $43.88^{\circ}, \mathrm{E} 125.35^{\circ}$ ) in 2014 summer. Among these hybrids, JNTG5, HO5598, and HO115 were high-oil type, and the others were common type (Table 1).

Table 1. Types and names of hybrids.
\begin{tabular}{l|l}
\hline Type & Name \\
\hline High-oil type & JNTG5, HO5598, HO115 \\
\hline Common type & $\begin{array}{l}\text { NH101, ZD958, XY335, JNTG1, JNTG2, JNTG3, JNTG4, JNTG6, JNTG7, JNTG8, } \\
\text { JNTG9, JNTG10, JNTG11, JNTG12, JNTG13, JNTG14, JNTG15, JNTG16 }\end{array}$ \\
\hline
\end{tabular}

These hybrids included the main heterotic patterns and shaft hybridization systems in production at present. Every cross combination was planted in two lines. The pollens of TG15 $\{($ Stock6 $\times$ CAU5 $) \times$ CAU5] $\times$ RWS $\} \times$ RWSwere collected after spinning for about 3 days, and 5 to 10 ears were found to be hybrid.

The hybrid ears from one combination were threshed and mixed after harvest. The identification procedure of haploid was as follow: first, primary identification was conducted according to grain color (Nanda and Chase, 1996; Wu et al., 2014): the putative haploids showed purple endosperm and non-purple embryo (Figure 1a), whereas the diploids (Diploid = Doubled haploid) showed purple endosperm and a strongly pigmented purple embryo (Figure

Genetics and Molecular Research 16 (1): gmr16019173 
1b). All putative haploids were seeded in Sanya $\left(\mathrm{N} 18.14^{\circ}, \mathrm{E} 109.31^{\circ}\right)$ examinational station in 2014 winter, and they were further identified according to their growth condition in fields, plant color, and tassel fertility. The diploids showed flourishing growth, purple stems, and fertilized tassels with high pollen dispersal. On the other hands, the haploids produced weak and small plants and unfertilized tassels or some fertilized ones (Figure 1c). Haploids with tassel pollen dispersal were selected and inbred. Haploid plants with powder in the tassel were selected for selfing in the flowering period. We investigated the natural fertility recovery degree according to the haploid appearance in fields: Powder rate of haploid = powder haploids/all haploids $\mathrm{x}$ $100 \%$; Seed setting rate of haploid $=$ seed setting haploids/all haploids x 100\%; Relative seed setting rate of haploid $=$ seed setting haploids/powder haploids $\mathrm{x} 100 \%$.

The powder haploids refer to the haploid plants having powder in the flowering stage in summer; the seed setting haploids refer to the haploid plants capable of producing kernels in the ears in autumn.
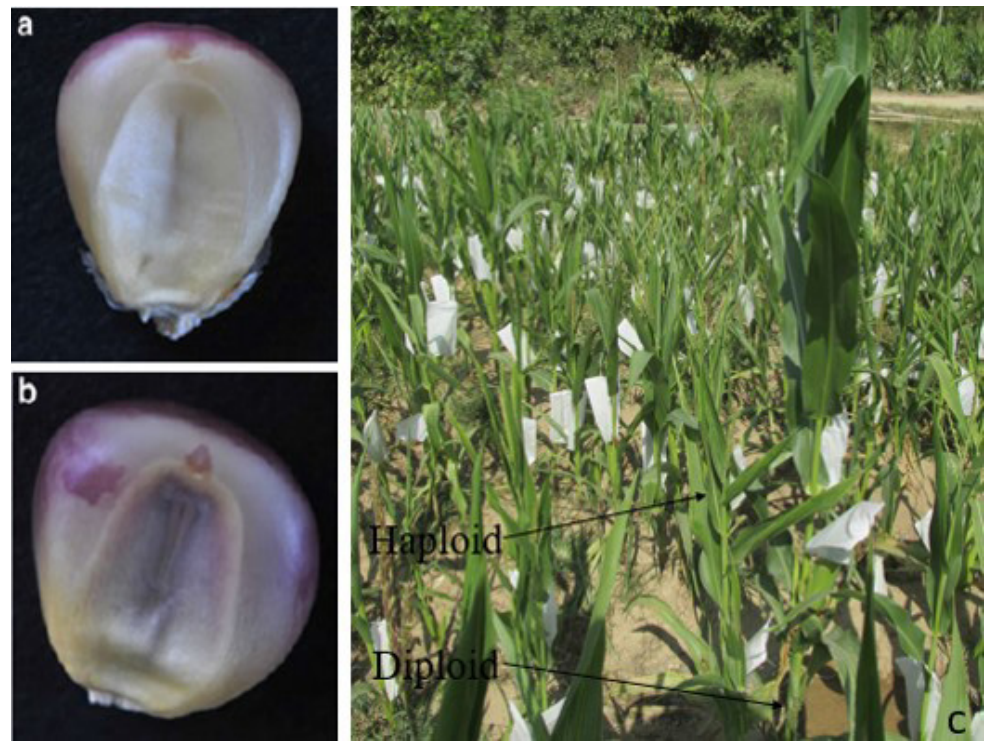

Figure 1. Different types of kernels produced from in vivo haploid induction by inducer TG15. a. Diploid kernel with purple endosperm and strongly pigmented purple embryo. b. Haploid kernel with purple endosperm and non-purple embryo. c. Haploid plants with upright leaves and plants small and weak, while diploid plants showed flourishing growth and purple stem.

\section{Bud-seedling double method and primary evaluation}

In this study, we established a new doubling method for haploids called bud seedling method. The top of a haploid bud was excised after its growth up to $2 \mathrm{~cm}$, immersed in colchicine, and then transplanted in a greenhouse and field. The basic procedures of the bud seedling method were established using materials from 21 different hybrid haploids in Changchun examinational station in 2015 summer (Table 1). Five hybrids (HO5598, ZD958, NH101, XY335, and JNTG5) were selected for investigating the doubling effects of different concentrations of colchicine (CK; 0.04, 0.06, and 0.08\%) at Sanya examinational station in 2015 winter. 


\section{RESULTS}

\section{Recovery of natural haploid fertility and chemical doubling}

Significant differences were observed in the natural recovery ability of tassels among different haploids (Figure 2). Most haploids were sterile with whole tassels showing no anther dehiscence (Figure 2a); some haploids showed partial recovery of fertilization with some opening anthers and powder on part branches (Figure 2b); some haploids showed all opening anthers, but shrinking and in dehiscence of the anthers with relatively lower fertilization (Figure 2c); some haploids showed normal powder and almost as much as diploids (Figure 2d).
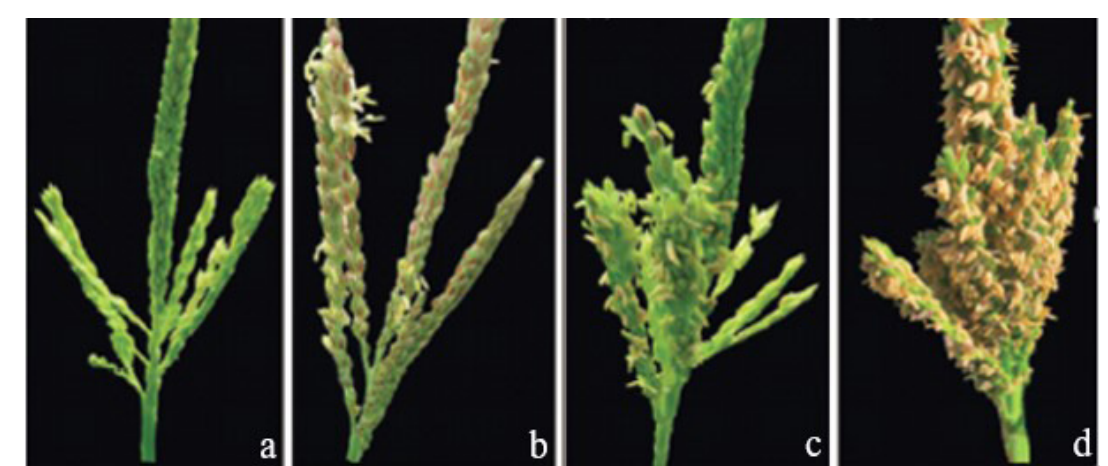

Figure 2. Variation of male fertility in haploid plants. a. Sterility. b. With fertile pollens in partial branch(es). c. Capable of flowering with low vigor. d. Capable of flowering with good vigor.

Significant differences were observed in the natural recovery ability of tassels among different genotypes. In this study, 21 hybrids were used as female parents, and were subjected to haploid induction. It had no statistical significance because of some genotypes with only a few haploids. Thus, we evaluated this part of haploids with mixed planting and they were described as "other" in the Table 2; the genotypes with more haploids were assessed separately (Table 2). The hybrid XY335 showed the highest powder rate (11.84\%) and HO115 showed the lowest $(4.12 \%)$ with a seed setting rate of only $1.23 \%$. However, some hybrid combinations, such as JNTG5 and HO5598 showed high powder rates and low seed setting rates. In all assessed 1462 haploids, 121 plants were capable of powdering, and their average powder rate was $8.28 \%$; approximately 50 grains could inbreed and fruit, their average and relative seed setting rates were 4.98 and $41.32 \%$, respectively.

Table 2. Genotypic effects on the spontaneous chromosome doubling of haploid plants in 2014 winter.

\begin{tabular}{|c|c|c|c|c|c|c|}
\hline Genotype & Number of haploids & $\begin{array}{c}\text { Number of haploid } \\
\text { with powder }\end{array}$ & $\begin{array}{l}\text { Number of haploids } \\
\text { with seed setting }\end{array}$ & Powder rate (\%) & Seed setting rate $(\%)$ & $\begin{array}{c}\text { Relative seed } \\
\text { setting rate }(\%)\end{array}$ \\
\hline JNTG5 & 273 & 24 & 1 & 8.79 & 0.37 & 4.17 \\
\hline HO5598 & 275 & 25 & 5 & 9.09 & 1.82 & 20.00 \\
\hline NH101 & 201 & 17 & 11 & 8.46 & 5.47 & 64.71 \\
\hline ZD958 & 204 & 20 & 9 & 9.80 & 4.41 & 45.00 \\
\hline HO115 & 243 & 10 & 3 & 4.12 & 1.23 & 30.00 \\
\hline XY335 & 76 & 9 & 9 & 11.84 & 11.84 & 100.00 \\
\hline Other & 190 & 16 & 12 & 8.42 & 6.32 & 75.00 \\
\hline Total & 1462 & 121 & 50 & 8.28 & 4.98 & 41.32 \\
\hline
\end{tabular}

Genetics and Molecular Research 16 (1): gmr16019173 
This study used the bud seedling method to produce double haploids in 2015 summer. Because plants need be treated at the seedling stage and then transplanted in fields in this method, some of the plants died in this process. The overall survival rate of treated plants was only $69.78 \%$. Among the survived plants, $40.10 \%$ were haploids as determined by their appearance in fields. As shown in Table 3, significant differences were observed in the doubling effects of haploids with different genotypes; even though it had a few haploids with different genotypes which were used in this experiment. Among these haploids, JNTG5 showed the lowest (5.13\%) and ZD958 showed the highest powder rate (42.50\%). Generally speaking, plant materials with relatively high powder rates should have high seed setting rates; however, we observed some exceptions. For example, the powder rate of HO5598 was $24.47 \%$, but its seed setting rate was only $4.26 \%$. On an average, 88 haploids had powder, and their powder rate was 26.04\%; approximately 50 haploids could fruit, and their seed setting rate was $14.79 \%$. The relative seed setting rate was $56.82 \%$ in the treated 338 haploids.

Table 3. Preliminary results of chromosome doubling in the young seedling stage in 2015 summer.

\begin{tabular}{|c|c|c|c|c|c|c|c|c|}
\hline Genotype & $\begin{array}{l}\text { Number of } \\
\text { transplants }\end{array}$ & $\begin{array}{c}\text { Number of } \\
\text { survived plants }\end{array}$ & $\begin{array}{c}\text { Number of } \\
\text { haploids }\end{array}$ & $\begin{array}{c}\text { Number of haploids } \\
\text { with powder }\end{array}$ & $\begin{array}{l}\text { Number of haploids } \\
\text { with seed setting }\end{array}$ & $\begin{array}{l}\text { Powder } \\
\text { rate }(\%)\end{array}$ & $\begin{array}{l}\text { Seed setting } \\
\text { rate }(\%)\end{array}$ & $\begin{array}{r}\text { Relative seed } \\
\text { setting rate }(\%)\end{array}$ \\
\hline JNTG5 & 116 & 68 & 39 & 2 & 2 & 5.13 & 5.13 & 100.00 \\
\hline HO5598 & 208 & 150 & 94 & 23 & 4 & 24.47 & 4.26 & 17.39 \\
\hline NH101 & 396 & 342 & 88 & 28 & 20 & 31.82 & 22.73 & 71.43 \\
\hline ZD958 & 110 & 49 & 40 & 17 & 10 & 42.50 & 25.00 & 58.82 \\
\hline HO115 & 265 & 16 & 43 & 12 & 8 & 27.91 & 18.60 & 66.67 \\
\hline XY335 & 113 & 72 & 34 & 6 & 6 & 17.65 & 17.65 & 100.00 \\
\hline Total & 1208 & 843 & 338 & 88 & 50 & 26.04 & 14.79 & 56.82 \\
\hline
\end{tabular}

In 2015 winter, different concentrations of colchicine were selected to double haploids based on the doubling method described in 2015 summer. The doubling effects were compared at different concentrations of colchicine. We found that in natural doubling method, the average powder rate and seed setting rate were $8.54 \%$ and $4.52 \%$, respectively, which were in agreement with the doubling method described in 2015 summer (Table 4). The powder rate and seed setting rate increased with increasing concentrations of colchicine. When the concentration of colchicine was $0.08 \%$, the average powder rate and seed setting rate were 35.53 and $20.30 \%$, respectively. As shown in Figures 3 and 4, an increase was observed in the powder rate and seed setting rate of each haploid plant with increasing concentrations of colchicine. However, the haploid HO5598 was an exception; its seed setting rate was lower than 0.06 at $0.08 \%$ colchicine. This might be related with the small sample size in statistical analysis.

\section{DISCUSSION}

\section{Natural recovery of haploid fertilization}

Even though haploids have one set of genome, they exhibit recovery of fertilizer to some extent, making the natural doubling of haploids possible. Several studies have shown that the degree of recovery of fertilizer was higher in female ears than tassels, and that the inbreeding and fruiting ability of haploids depended on tassels. Chalyk et al. (1994) reported that 234 haploid female ears were pollinated with other maize pollens, in which $97 \%$ ears showed seed setting, and the average ear produced 26 grains. The maximum number of

Genetics and Molecular Research 16 (1): gmr16019173 
Table 4. Comparison of the haploid chromosome doubling efficiency under four concentrations of colchicine in 2015 winter.

\begin{tabular}{|c|c|c|c|c|c|c|}
\hline Concentration $\%$ & Material & $\begin{array}{c}\text { Number of surviving } \\
\text { haploids }\end{array}$ & $\begin{array}{l}\text { Number of haploids } \\
\text { with powder }\end{array}$ & $\begin{array}{l}\text { Number of haploids } \\
\text { with seed setting }\end{array}$ & Powder rate $(\%)$ & Seed setting rate $(\%)$ \\
\hline \multirow[t]{6}{*}{ CK (Colchicine) } & HO5598 & 66 & 3 & 2 & 4.55 & 3.03 \\
\hline & NH101 & 39 & 5 & 3 & 12.82 & 7.69 \\
\hline & XY335 & 29 & 2 & 1 & 6.90 & 3.45 \\
\hline & ZD958 & 65 & 7 & 3 & 10.77 & 4.62 \\
\hline & JNTG5 & 32 & 2 & 1 & 6.25 & 3.13 \\
\hline & Total & 199 & 17 & 9 & 8.54 & 4.52 \\
\hline \multirow[t]{6}{*}{0.04} & HO5598 & 35 & 5 & 2 & 14.29 & 5.71 \\
\hline & NH101 & 40 & 6 & 2 & 15.00 & 5.00 \\
\hline & $\mathrm{XY} 335$ & 40 & 6 & 2 & 15.00 & 5.00 \\
\hline & ZD958 & 56 & 9 & 5 & 16.07 & 8.93 \\
\hline & JNTG5 & 48 & 4 & 4 & 8.33 & 8.33 \\
\hline & Total & 171 & 26 & 11 & 15.20 & 6.43 \\
\hline \multirow[t]{6}{*}{0.06} & HO5598 & 61 & 13 & 11 & 21.31 & 18.03 \\
\hline & NH101 & 61 & 16 & 9 & 26.23 & 14.75 \\
\hline & XY335 & 86 & 14 & 6 & 16.28 & 6.98 \\
\hline & ZD958 & 64 & 16 & 9 & 25.00 & 14.06 \\
\hline & JNTG5 & 45 & 6 & 2 & 13.33 & 4.44 \\
\hline & Total & 272 & 59 & 35 & 21.69 & 12.87 \\
\hline \multirow[t]{6}{*}{0.08} & HO5598 & 40 & 8 & 2 & 20.00 & 5.00 \\
\hline & NH101 & 61 & 30 & 24 & 49.18 & 39.34 \\
\hline & XY335 & 46 & 12 & 4 & 26.09 & 8.70 \\
\hline & ZD958 & 50 & 20 & 10 & 40.00 & 20.00 \\
\hline & JNTG5 & 47 & 14 & 10 & 29.79 & 21.28 \\
\hline & Total & 197 & 70 & 40 & 35.53 & 20.30 \\
\hline
\end{tabular}

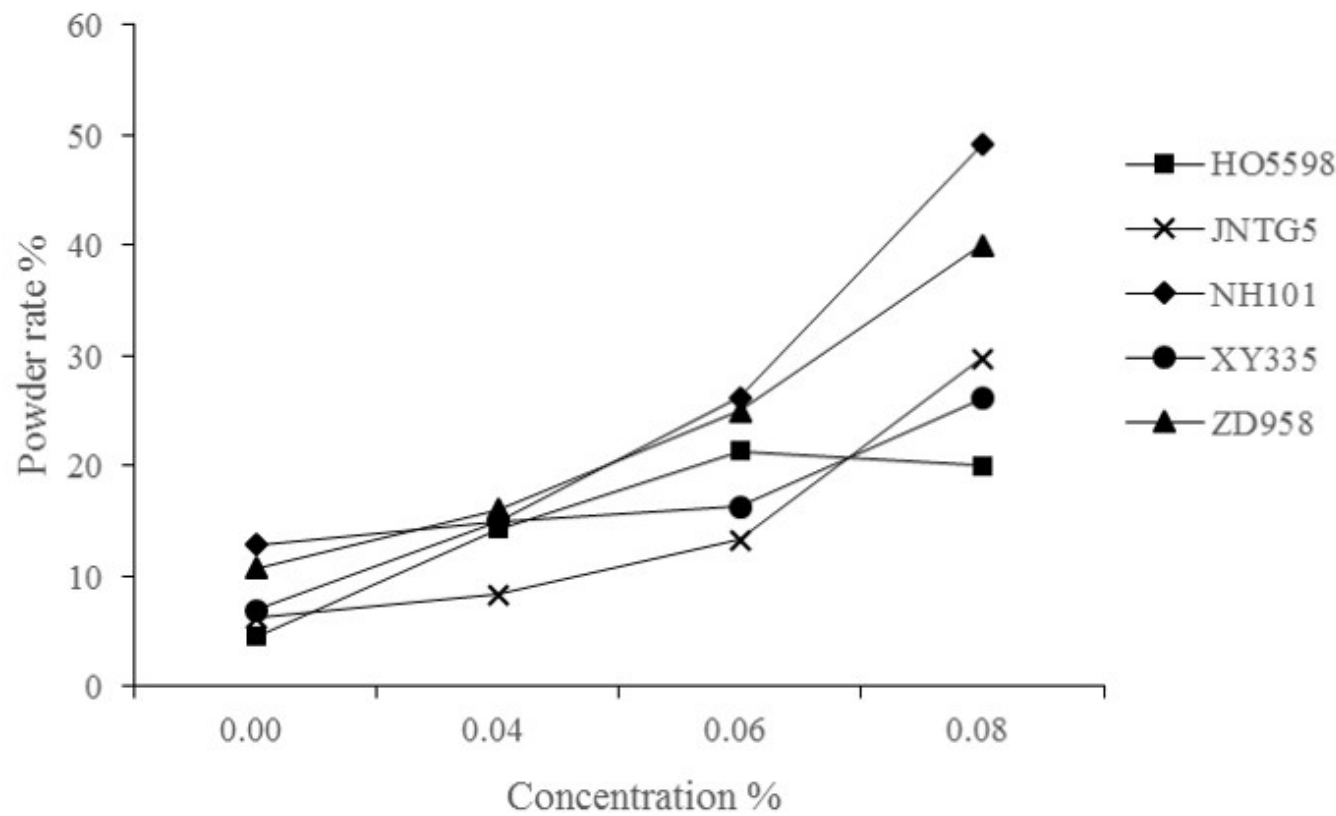

Figure 3. Comparison of haploid powder rate.

Genetics and Molecular Research 16 (1): gmr16019173 


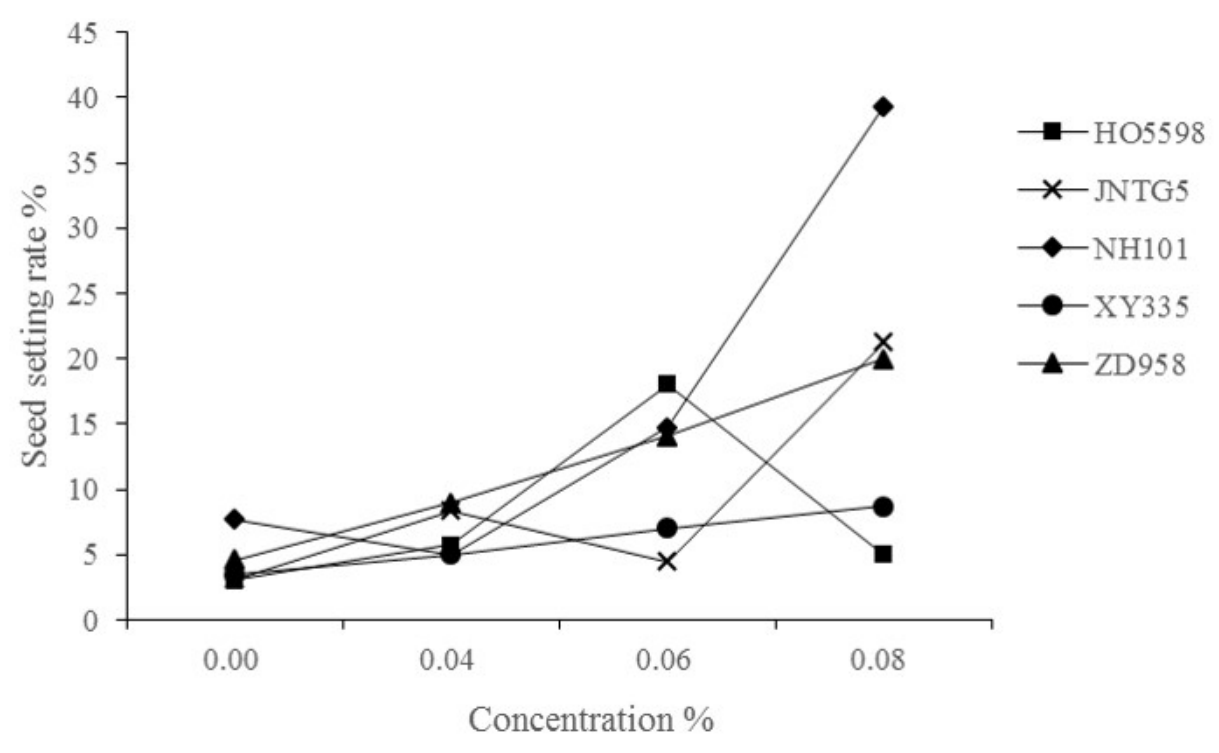

Figure 4. Comparison of haploid seed setting rate.

grains produced by an ear was 107 . Geiger et al. (2006) obtained more grains per ear. Liu and Song (2000) also found the similar results. Therefore, the powder rate of tassels could be considered as a standard in doubling studies at present. However, our study found that the non-coordination of female and male led to production of tassel powder, but did not obtain any inbred grains probably because of the female plant materials used in our study.

Our study mainly focused on the recovery of tassels fertilizer. Although the size of study materials was small, but significant differences were found in the powder rate among offspring of different plant materials, while the seed setting rate was much larger (Tables 2 and 4). The fertilizer recovery of maize haploid tassels was commonly low. Chase's study revealed that natural doubling rate of haploids was about 1\% (Chase, 1952). Chalyk et al. (1994) studied a total of 1634 haploids for two years and found that only 2.6 and $3.3 \%$ haploids were capable of inbreeding and fruiting, respectively. The seed setting rate was slightly higher in this study than the previous studies. Thus, it was crucial to conduct artificial doubling of haploids to obtain more inbred offspring.

The difference in fertilization recovery among haploids of different genotypes revealed that the fertilization might be genetically controlled. Zabirova et al. (1993) even reported an offspring haploid with very strong recovery of fertilization; its inbred seed setting rate was $33 \%$, which was obtained after four times of fertilization recovery. Some studies demonstrated that the haploids exhibited relatively higher fertilization recovery rates after multiple inductions than the common method (Shatskaya et al., 1994; Gayen and Sarkar, 1996; Testillano et al., 2004). They considered that the fertilization of haploid tassels was controlled by nuclear genes in an additive manner. Furthermore, we determined the powder and seed setting rate of hybrid ZD958 offspring after natural or artificial doubling, and suggested that a high fertilization recovery rate was needed for further study. Except for genotypes, Liu and 
Song (2000) reported that the planting environments had a close relationship with fertilization recovery, and they thought that natural fertilization recovery of haploid tassels had positive (or negative) correlation with the change in environmental temperature at the early growth stage (or diurnal amplitude). Due to the limited study environments and materials, our results needed further confirmation. The fertilization recovery of genotypes and environmental differences suggested that we could select materials with high fertilization recovery to develop haploid breeding and suitable stations for natural doubling of haploids.

The mechanism of the natural recovery of haploid fertilization is unclear yet. Gayen et al. (1994) studied the pollen mother cells of maize, and observed that the protoplast fusion occurred among cells, and the chromatin transferred from one cell to another one. They thought that it had a close relationship with the improvement of pollen fertilization and seed setting of female ears. Chalyk et al. (1994) reported that Khoklov studied 17,800 somatic cells of maize haploids, and found that $0.42 \%$ of them were diploids. It was clear that the haploid somatic cells had a natural diploidization tendency, but it was unclear whether this phenomenon had a relationship with protoplast fusion. Testillano et al. (2004) reported that chromosome doubling occurred during the formation of microspores in early-stage embryogenesis during the culture of maize in vitro, and considered that karyomixis might induce the chromosome doubling. Some researchers attributed some other factors, such as endoreduplication, endomitosis, and fusion of sperm and vegetative nucleus in pollen tube, to chromosome doubling (Jensen, 1974; Testillano et al., 2004). Wei et al. (2003) studied the somatic cells and pollen mother cells from 10 haploids, and found that 9 plants had certain proportion of diploid cells, and only 3 plants were with $n$ $=20$ chromosomes; however, the rate of diploidization was higher in pollen mother cells as compared to somatic cells. Therefore, they held that the diploidization of somatic haploid cells was the premise of the existence of diploid cells in sexual cells. It could be inferred that haploids had a possibility of diploidization in the whole growth period; once the diploidization occurred in sexual cells, they could produce the fertilized pollens. Different haploids showed different degree of fertilization recovery (Figure 2). In haploids, some individual flowers were fertilized, some were partial branches, and some were whole tassels, indicating that it was caused by the diploidization of sexual cells at different periods. In recent years, few studies have focused on the diploidization of somatic or sexual cells (Tang et al., 2009). Study on recovery mechanism could largely help us to better understand the natural doubling of haploids, enabling us to take measures to promote the diploidization of haploids cells.

\section{Efficient methods of haploid doubling}

The haploids showed different degrees of fertilization recovery; however, the population frequency was still too low to meet breeding specifications. Therefore, artificial doubling was the primary method of haploid doubling, in which colchicine, an inhibitor of cell division, is mostly applied for doubling haploids. When compared with other crops, the doubling of maize haploids was very difficult, with different genotypes of maize showing large differences in haploid doubling response. Therefore, researchers tried to identify various methods of haploid doubling, but none were ideal. At last, Gayen et al. (1994) gained a breakthrough progress, in which bud tips were cut off and treated with colchicine. However, these results were not enough to satisfy the need of breeding yet. Our study was based on the results of previous studies, and to our knowledge it is the first report of the doubling method of haploids named "bud seedling method" in China. Among different concentrations of colchicine

Genetics and Molecular Research 16 (1): gmr16019173 
used for haploid doubling, we found that the $0.08 \%$ colchicine provided better results than $0.06 \%$, and the powder was observed in all plant materials treated with over $20 \%$ colchicine. Eder and Chalyk (2002) reported that in different plant materials, the average doubling rate obtained by using the bud seedling method was $49 \%$, which was significantly higher than that obtained by using the injection method at 3 to 4 -leaf stage (16\%). The doubling effects observed in this study were obviously different from those observed in the previous reports; this might be related to the difference in plant materials and planting environments, not in the doubling methods. Besides colchicine concentration, other factors, such as adjuvant, temperature of treatment, soaking time, planting environments, etc., have an influence on the doubling effects. Therefore, it is important to explore all factors that might influence the doubling effects of haploids in order to find the best factor combination for optimal haploid doubling and complete the standards of haploid doubling.

Although colchicine provides better doubling effects, it shows high toxicity. It not only induces malformation or death in seedlings, but also poses great risk to human health. Therefore, finding a new chemical substitute for colchicine was an important part of the studies on haploids doubling. Recently, some cell division inhibitors with similar functions, such as amiprophosmethyl (APM), pronamide, oryzalin, and trifluralin, were proved to have better doubling effects. Kato and Geiger (2002) reported that nitrous oxide $\left(\mathrm{N}_{2} \mathrm{O}\right)$ showed good doubling effects; however, the facility used in doubling was too special to influence its application at a large scale. Häntzschel and Weber (2010) developed the selected system using the root tips of maize, which also proved that the herbicides, APM and pronamide, had better doubling effects. Therefore, it was necessary to focus on these herbicides to find their best treatment concentration and method for haploid doubling. At the same time, it was still necessary to establish an effective drug selection system, and to find the safe and effective doubling regents.

Besides chemical regents, another important aspect was assisted pollination. Generally speaking, pollens from an anther could obtain a few grains to multiply offspring; however, mostly the anthers do not succeed in powdering after successful doubling. Therefore, assisted pollination could largely improve the rate of inbred grains by promoting the powdering of anthers and fully using the pollens of tassels.

\section{Conflicts of interest}

The authors declare no conflict of interest.

\section{ACKNOWLEDGMENTS}

Research supported by funds from the National Spark Plan Project (\#2015GA660007) and the Chinese Universities Scientific Fund (\#15053201). The authors greatly appreciate the helpful comments and suggestions from Dr. Ci Jiabin who worked in the School of Agronomy in Jilin Agricultural University and other anonymous reviewers.

\section{REFERENCES}

Cai Z, Xu GL, Ren J, Zhan MT, et al. (2013). Technique specifications for the breeding of maize inbred line using haploid induction from cross hybridization. J. Maize Sci. 21: 1-5.

Chalyk ST, Bylich VG and Chebotar OD (1994). Transgressive segregation in the progeny of a cross between two inducers of maize maternal haploids. Maize Genet. Coop. Newsl. 68: 47.

Genetics and Molecular Research 16 (1): gmr16019173 
Chase SS (1952). Produciton of homozygous diploids of maize from monoploids. Agron. J. 44: 263-267. http://dx.doi. org/10.2134/agronj1952.00021962004400050010x

Dong ZS, Lu H, Chai YC and Cai Z (2015). Concept and practices of maize commercial breeding in China. J. Maize Sci. 23: 1-9.

Eder J and Chalyk S (2002). In vivo haploid induction in maize. Theor. Appl. Genet. 104: 703-708. http://dx.doi. org/10.1007/s00122-001-0773-4

Geiger HH, Braun MD, Gordillo GA, Koch S, et al. (2006). Variation for female fertility among haploid maize lines. Maize Genet. Coop. Newsl. 80: 28-29.

Gayen P and Sarkar KR (1996). Cytomixis in maize haploids. Indian J. Genet. Plant Breed. 56: 79-85.

Gayen P, Madan JK, Kumar R and Sarkar KR (1994). Chromosome doubling in haploids through colchicine. Maize Genet. Coop. Newsl. 68: 65.

Häntzschel KR and Weber G (2010). Blockage of mitosis in maize root tips using colchicine-alternatives. Protoplasma 241: 99-104. http://dx.doi.org/10.1007/s00709-009-0103-2

Jensen SJ (1974). Chromosome doubling techniques in haploids. In: Haploids in higher plants - Advances and potential (Kasha KJ, ed.). Guelph University Press, Guelph, Canada 153-190.

Jiang L, Ci JB, Cui XY, Zhang Y, et al. (2014). Study on induction rate and doubling rate of maize haploid under different ecological conditions. J. Jilin Agric. Univ. 2.139-143.

Kato A and Geiger H (2002). Chromosome doubling of haploid maize seedlings using nitrous oxide gas at the flower primordial stage. Plant Breed. 121: 370-377. http://dx.doi.org/10.1046/j.1439-0523.2002.743321.x

Liu ZZ and Song TM (2000). The breeding and identification of haploid inducer with high frequency parthenogenesis in maize. Acta Agron. Sin. 26: 570-574.

Nanda DK and Chase SS (1996). An embryo marker for detecting monoploids of maize (Zea mays L.). Crop Sci. 6: 213215. http://dx.doi.org/10.2135/cropsci1966.0011183X000600020036x

Prigge V, Xu X, Li L, Babu R, et al. (2012). New insights into the genetics of in vivo induction of maternal haploids, the backbone of doubled haploid technology in maize. Genetics 190: 781-793. http://dx.doi.org/10.1534/ genetics.111.133066

Shatskaya OA, Zabirova ER and Shcherbak VS (1994). Autodiploid lines as sources of haploid spontaneous diploidization in corn. Maize Genet. Coop. Newsl. 68: 51-52.

Testillano P, Georgiev S, Mogensen HL, Coronado MJ, et al. (2004). Spontaneous chromosome doubling results from nuclear fusion during in vitro maize induced microspore embryogenesis. Chromosoma 112: 342-349. http://dx.doi. org/10.1007/s00412-004-0279-3

Tang QL, Feng YC, Han XL, Zheng MM, et al. (2009). Study on haploid inducing and its meiotic abnormality in maize. Agric. Sci. China 8: 1159-1165. http://dx.doi.org/10.1016/S1671-2927(08)60325-9

Wu PH, Ren JJ, Li L and Chen SJ (2014). Early spontaneous diploidization of maternal maize haploids generated by in vivo haploid induction. Euphytica 200: 127-138. http://dx.doi.org/10.1007/s10681-014-1166-5

Wei JJ, Li HM and Liu ZZ (2003). Cytology study of maize haploid. J. Baoding Teach. Coll. 16: 21-33.

Xu GL, Dai YX and Liu XD (2012). Research on the induced rates and the doubling rates of haploid in maize. J. Maize Sci. 20: 1-5.

Xu X, Li L, Dong X, Jin W, et al. (2013). Gametophytic and zygotic selection leads to segregation distortion through in vivo induction of a maternal haploid in maize. J. Exp. Bot. 64: 1083-1096. http://dx.doi.org/10.1093/jxb/ers393

Zhao X, Xu X, Xie H, Chen S, et al. (2013). Fertilization and uniparental chromosome elimination during crosses with maize haploid inducers. Plant Physiol. 163: 721-731. http://dx.doi.org/10.1104/pp.113.223982

Zabirova ER, Shatskaya OA and Shcherbak VS (1993). Line 613/2 as a source of a high frequency of spontaneous diploidization in corn. Maize Genet. Coop. Newsl. 67: 67.

Genetics and Molecular Research 16 (1): gmr16019173 